\title{
OPTIMIZATION OF EXTRACTION PARAMETERS FOR TOTAL FLAVONOIDS FROM GARDENIA GUMMIFERA GUM RESIN BY RESPONSE SURFACE METHODOLOGY
}

\author{
SNEHAL B. BHANDARE*, KIRTI S. LADDHA \\ Medicinal and Natural Product Research Laboratory, Department of Pharmaceutical Sciences and Technology, Institute of Chemical \\ Technology, Matunga, Mumbai, India 400019 \\ Email: snehalbhandare28@yahoo.com
}

Received: 07 Feb 2016 Revised and Accepted: 09 Sep 2016

\begin{abstract}
Objective: To optimize the extraction parameters for determining the highest yield of Total Flavonoids from Gardenia gummifera gum resin.

Methods: In the present study, response surface methodology (RSM) with three level Box Behenken design (BBD) was performed to optimize extraction parameters for total flavonoids. Solvent concentration(A), extraction time (B) and extraction temperature(C) were considered for single
\end{abstract} factor experiment.

Results: The highest flavonoid concentration was obtained with acetone $45.00 \% \mathrm{v} / \mathrm{v}$, time 101.46 min, temperature $41.57{ }^{\circ} \mathrm{C}$. The average experimental TFC under optimal conditions was $161.14 \mathrm{mg} / \mathrm{g}$ which was in close agreement with the predicted value of $163.42 \mathrm{mg} / \mathrm{g}$.

Conclusion: RSM-BBD is successfully applied in optimizing extraction conditions for extraction of total flavonoids from G. gummifera gum resin.

Keywords: G. gummifera, Response Surface Methodology, Box-Behnken design, Total Flavonoid Content

(C) 2016 The Authors. Published by Innovare Academic Sciences Pvt Ltd. This is an open access article under the CC BY license (http://creativecommons. org/licenses/by/4. 0/)

DOI: http://dx.doi.org/10.22159/ijpps.2016v8i11.11134

\section{INTRODUCTION}

The biologically active compounds from natural sources have gained interest as they are obtained from renewable sources, having low toxicity, biodegradability and low cost. A wide range of phytochemicals and polyphenolic compounds such as phenolic acids, flavonoids, tannins, etc are derived from plants [1]. Flavonoids are secondary plant phenolics consisting of the flavan nucleus. Flavonoids have gained a lot of attention by biochemical and nutritional researchers as they have various biological activities which include antibacterial, antiviral, antioxidant, antiradical, antiallergic, anti-inflammatory, anti-neuro toxic, anti-cancer effects, cardioprotective are used in health care, food or medicine [2,3].

G. gummifera Linn. Belonging to the family Rubiaceae, is a shrub found in Deccan peninsula to Bundel khand and parts of Bihar. Gum resin secretions called Dikamali or Cumbi gum are greenish yellow in color, have a very pungent taste and an offensive odour [4]. It has antispasmodic, diaphoretic, expectorant, carminative, anthelmintic properties as well as used in veterinary practices. Commercial sample of Dikamali constituted resin, 89.9; volatile oil, 0.1; and other impurities, $10.0 \%$. The resin is abundant in polymethoxylated flavonoids (PMF) accounting flavones such as gardenin A-E, nevadensin, isoscutellarein, apigenin and woganins ( $>50 \%$ of total), hence is chosen for research purpose $[4,5]$.

In order to develop plant extract as a new active ingredient for functional food, nutraceuticals and cosmetics; the optimal extraction of flavonoid compound is an important step. For the commercial application of the process, determination of the optimal operating conditions is necessary. Several parameters that influence the extraction yield are the extraction method and technology, type and concentration of solvent, extraction temperature, extraction time, the solvent to solid ratio, extraction number, $\mathrm{pH}$ and particle size. RSM technique helps to evaluate the interactive effect of these parameters instead of evaluating each parameter individually. RSM is a collection of statistical and mathematical techniques that allow the user to identify optimal conditions for a selected response while minimizing the number of required experiments [6, 7]. As heat reflux is simple and commonly used method for extraction of compounds; in this research, BBD of RSM was applied to optimize significant variables like acetone concentration, extraction time and temperature that affect TFC of G. gummifera gum resin.

\section{MATERIALS AND METHODS}

\section{Materials}

G. gummifera gum resin was purchased from local market of Mumbai, India. The plant was identified and its voucher specimen was deposited at the herbarium of Department of Pharmaceutical Sciences and Technology, Institute of Chemical Technology, Mumbai. Rutin was purchased from Total Herb Solutions, Mumbai. Analytical grade Aluminium chloride was purchased from S D Fine Chemicals Ltd. Deionized water was purified by milli-Q academic water Purification system and solvents used for extraction were of analytical grade.

\section{Extraction of flavonoids}

Gum resin of G. gummifera was ground to fine powder using mortar and pestle. Five gram of sample was transferred into $100 \mathrm{ml}$ round bottom flask and reflux extracted in a water bath with $50 \mathrm{ml}$ of water, petroleum ether, methanol, ethanol, acetone, ethyl acetate, and chloroform separately for $3 \mathrm{~h}$ at their boiling points for solvent selection. Extracts of various solvents were filtered using filter paper and concentrated to obtain dry extracts. Further $1 \mathrm{mg} / \mathrm{ml}$ solution was made in methanol for determination of TFC expressed as mg of rutin equivalents/g of extract. As acetone extract gave high TFC, samples were prepared in different aqueous acetone concentrations $(20 \%, 40 \%, 60 \%$ and $80 \% \mathrm{v} / \mathrm{v})$ within given ranges of temperature $\left(30^{\circ} \mathrm{C}\right.$ to $\left.70{ }^{\circ} \mathrm{C}\right)$ and extraction time $(30$ to $150 \mathrm{~min})$ to determine TFC. All extractions were carried out in triplicate.

\section{Determination of TFC in the plant extracts}

The TFC was determined spectrophotometrically [8, 9]. Briefly, 0.5 $\mathrm{ml}$ of $2 \%$ solution of $\mathrm{AlCl}_{3}(\mathrm{w} / \mathrm{v})$ in methanol was mixed with the same volume of extract $(1 \mathrm{mg} / \mathrm{ml})$. Absorption readings at $430 \mathrm{~nm}$ were taken after $15 \mathrm{~min}$, against a blank (methanol+ $0.5 \mathrm{ml}$ of $2 \%$ solution of $\mathrm{AlCl}_{3}$ (w/v) using UV Spectrophotometer (JASCO V-530 UV-visible spectrophotometer).

The TFC was determined using rutin as calibration standard over the range of $0-40 \mu \mathrm{g} / \mathrm{ml}$. All measurements were repeated three times. 
The calibration curve was $y=0.017 x+0.089$, where $y=a b s o r b a n c e$ value and $x=$ sample concentration of flavonoids; $\mathrm{R}^{2}=0.997$.

\section{Experimental design and statistical analysis}

The TFC depends on extraction process and parameters used. Parameters which had a major effect on TFC were selected based on preliminary experiments. It is reported that TFC is affected by solvent concentration, extraction temperature, extraction time and hence these parameters were screened by single factor experiment [10].

Given the preliminary result, a second order polynomial model corresponding to the BBD was fitted to correlate the relationship between the independent variables, namely acetone concentration (A), extraction time (B), extraction temperature (C) and response (TFC) to predict the optimized conditions that are listed in table 1 . The complete design consisted of 17 experimental runs, including 5 replicates of the center points.
The response variable was fitted by second order polynomial model as follows:

$$
Y=\beta_{0}+\sum_{i=0}^{3} \beta_{i} X_{i}+\sum_{j=0}^{3} \beta_{i i} X_{i}^{2}+\sum \sum_{i<j=1}^{3} \beta_{i j} X_{i} X_{j}
$$

Where $\mathrm{Y}$ is the predicted response; $\beta_{0}$ is the intercept coefficient which corresponds to theoretical TFC at the center of experimental design; $\beta_{i}, \beta_{i i}, \beta_{i j}$ linear, quadratic and interaction coefficient; $X_{i}$ and $X_{j}$ are the coded independent variables; $X_{i} X_{j}$ and $\mathrm{X}_{\mathrm{i}}^{2}$ are the interaction and quadratic terms respectively.

The Design-Expert software (trial version 9.0.3.1, Stat-Ease Inc., Minneapolis, USA) was utilized for the experimental design, multiple regression analysis $\left(\mathrm{R}^{2}\right)$, ANOVA, and the numerical optimization of the Response Surface Regression (RSREG) procedure. These practical values were compared with those of the predicted values to check the validity of the model.

Table 1: Variables and their levels for Box Behenken design

\begin{tabular}{llll}
\hline Independent variables & Coded symbols & levels & \\
\cline { 2 - 4 } & & $\mathbf{- 1}$ & $\mathbf{0}$ \\
\hline Acetone concentration $(\% \mathrm{v} / \mathrm{v})$ & $\mathrm{A}$ & 20 \\
Extraction time $($ min) & $\mathrm{B}$ & 60 & 60 \\
Extraction Temperature $\left({ }^{\circ} \mathrm{C}\right)$ & $\mathrm{C}$ & 90 & 40 \\
\hline
\end{tabular}

\section{RESULTS AND DISCUSSION}

\section{Effect of solvent types on extraction of total flavonoids}

Solvent plays an important role in the extraction of flavonoids. So, various polar to non-polar solvents such as water, ethanol, methanol, acetone, ethyl acetate, chloroform and petroleum ether were taken for extraction of flavonoids.

The extracts obtained were screened for TFC. Fig. 1 indicates maximum flavonoid content in an acetone extract compared to any other solvent extract and hence selected for further extraction.

\section{Effect of acetone concentration on extraction of TFC}

It has been revealed that polar solvents when mixed with water, extracts phenolic compounds, more efficiently than single solvent due to increase in polarity [11]. A Higher proportion of water $(>30 \%)$, improved the extraction of other polyphenolic compounds [12]. Acetone extract $(80 \% \mathrm{v} / \mathrm{v})$ provides the most complete extraction of phenolic compounds from lentil seeds, especially flavonols and condensed tannins. Wild blueberry leaves extracted with acetone $(70 \% \mathrm{v} / \mathrm{v})$, showed a higher level of crude tannins compared with that extracted with ethanol $(95 \% \mathrm{v} / \mathrm{v})$ [13].

Hence to study the effect of acetone and deionized water on TFC in various acetone concentration $(20 \%, 40 \%, 60 \%, 80 \% \mathrm{v} / \mathrm{v})$ were prepared for extraction. Fig. 2 indicates that various acetone concentrations affect the TFC of G. gummifera gum resin. At $20 \% \mathrm{v} / \mathrm{v}$ and $40 \% \mathrm{v} / \mathrm{v}$ of acetone concentration the TFC was found to be $34.92 \mathrm{mg} / \mathrm{g}$ and $128.16 \mathrm{mg} / \mathrm{g}$ respectively. But it decreased when the concentration of acetone is increased beyond $40 \%$. Thus highest TFC $(128.16 \mathrm{mg} / \mathrm{g})$ was seen at $40 \%$ $\mathrm{v} / \mathrm{v}$ acetone concentration. Hence, for determining the effect of extraction time and extraction temperature on TFC $40 \%(\mathrm{v} / \mathrm{v})$ acetone was selected.

\section{Effect of extraction time on extraction of TFC}

Fig. 3 indicates the effect of time on the TFC. Extraction was carried out using $40 \% \mathrm{v} / \mathrm{v}$ acetone as the solvent for extraction, with extraction time $(30,60,90,120$ and $150 \mathrm{~min})$ to calculate TFC. In general increase in extraction time increases the extraction rate. As time was increased from $30 \mathrm{~min}$ to $90 \mathrm{~min}$, there was an increase in TFC. At $90 \mathrm{~min}$, TFC was found to be $132.84 \mathrm{mg} / \mathrm{g}$ which was highest. After $90 \mathrm{~min}$, there was a slight decrease in TFC which may be due to degradation of active compound during prolonged extraction time [14]. Shorter extraction time led to maximum flavonoid extraction, making it more economical and practical method. Hence, 90 min extraction time was optimized for RSM as the center point.

\section{Effect of extraction temperature on extraction of TFC}

Under the above optimal conditions of acetone concentration $40 \% \mathrm{v} / \mathrm{v}$ and extraction time $90 \mathrm{~min}$, effects of different extraction temperatures $\left(30^{\circ}, 40^{\circ}, 50^{\circ}, 60^{\circ}, 70^{\circ} \mathrm{C}\right)$ on the TFC were determined.

Fig. 4 indicates the effect of temperature on extraction of flavonoids. Extraction temperature also plays a pivotal role in the extraction of flavonoids [15]. Increase in the extraction temperature favors extraction by increasing the solubility of solute, but phenolic compounds undergo denaturation beyond a certain temperature due to internal redox reactions, hydrolysis and polymerization [16]. Hence an optimum temperature needs to be selected. There is an increase in flavonoid content with increase in temperature from 30 to $50^{\circ} \mathrm{Cbeyond}$ which a decrease in TFC was found. Highest TFC found at $50^{\circ} \mathrm{C}$ that $125.84 \mathrm{mg} / \mathrm{g}$ and hence $50^{\circ} \mathrm{C}$ was selected as extraction temperature for RSM.

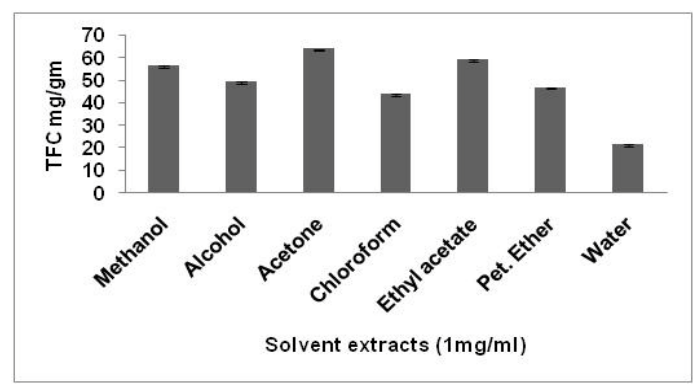

Fig. 1: Effect of various solvents on the total flavonoid content from G. gummifera gum resin. Error bars indicate SD for $n=3$

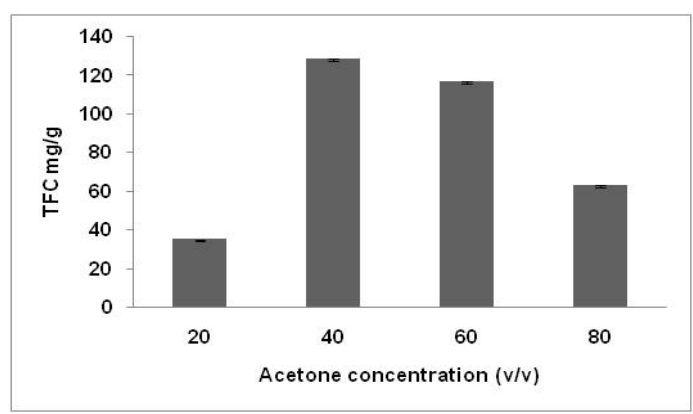

Fig. 2: Effect of acetone concentration on the extraction of total flavonoids from G. gummifera gum resin for $180 \mathrm{~min}$. Error bar indicates SD for $n=3$ 


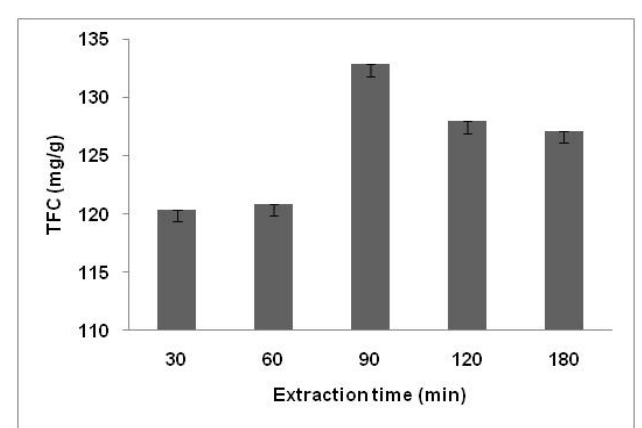

Fig. 3: Effect of extraction time on the extraction of total flavonoids from G. gummifera gum resin using $40 \% \mathrm{v} / \mathrm{v}$ acetone. Error bars indicate SD for $n=3$

\section{Optimization of the procedure}

\section{1) The model fitting and statistical analysis}

Results of single factor experiment i.e. acetone concentration, extraction time and extraction temperature on the TFC were taken into consideration for experimental design by RSM. A set of 17 experiments were carried out for optimizing TFC in G. gummifera gum resin in BBD. Table 2 shows the experimental conditions and TFC according to factorial design.

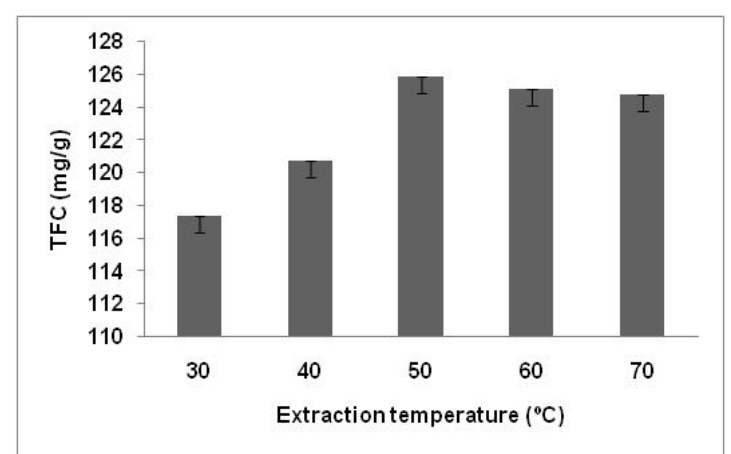

Fig. 4: Effect of extraction temperature on the extraction of total flavonoids from G. gummifera gum resin using $40 \% \mathrm{v} / \mathrm{v}$ acetone for $90 \mathrm{~min}$. Error bars indicate SD for $\mathrm{n}=3$

Table 2: Box Behenken experimental design and result

\begin{tabular}{|c|c|c|c|c|}
\hline Run & A (Concentration in $\% \mathrm{v} / \mathrm{v})$ & B (Time in min) & $\mathrm{C}$ (Temperature in $\left.{ }^{\circ} \mathrm{C}\right)$ & TFC (mg/g) \\
\hline 1 & 60 & 90 & 60 & 78.4 \\
\hline 2 & 40 & 120 & 40 & 152.72 \\
\hline 3 & 20 & 120 & 50 & 26.92 \\
\hline 4 & 40 & 90 & 50 & 144.4 \\
\hline 5 & 40 & 60 & 60 & 143.08 \\
\hline 6 & 20 & 90 & 40 & 67.78 \\
\hline 7 & 60 & 90 & 40 & 130.22 \\
\hline 8 & 20 & 90 & 60 & 29.42 \\
\hline 9 & 60 & 120 & 50 & 99.8 \\
\hline 10 & 60 & 60 & 50 & 96.34 \\
\hline 11 & 20 & 60 & 50 & 44.98 \\
\hline 12 & 40 & 90 & 50 & 141.66 \\
\hline 13 & 40 & 90 & 50 & 147.2 \\
\hline 14 & 40 & 120 & 60 & 116.86 \\
\hline 15 & 40 & 60 & 40 & 146.28 \\
\hline 16 & 40 & 90 & 50 & 156.46 \\
\hline 17 & 40 & 90 & 50 & 128.22 \\
\hline
\end{tabular}

By applying multiple regression analysis on the experimental data, the response variables and the test variables were related by the following second-order polynomial equation:

Final equation in terms of coded factors

$\mathrm{Y}=143.59+29.46 \mathrm{~A}-4.3 \mathrm{~B}-16.16 \mathrm{C}+5.38 \mathrm{AB}-3.37 \mathrm{AC}-8.17 \mathrm{BC}-69.93 \mathrm{~A}^{2}-$ $6.65 \mathrm{~B}^{2}+2.8 \mathrm{C}^{2} \ldots(2)$

Where $\mathrm{A}$ is acetone concentration, $\mathrm{B}$ is time; $\mathrm{C}$ is the temperature in coded language respectively.

ANOVA analysis was conducted in order to determine the significance of the experimental model. The experimental result has been found to be well fitted when a model has a significant regression and an insignificant lack of fit. The lack of fit statistics detects the adequacy of the model which indicated that the P-value of 0.4417 was not significant as summarized in table 3 hence the model is significant.

The P-values were used as tools to check the significance of each coefficient and the interaction strength of each parameter. The smaller the P-values are, the bigger the significance of the corresponding coefficient. Here, the P-value of the model was smaller than 0.0001, which indicated that the model was suitable for use in this experiment. The determination coefficient $\left(\mathrm{R}^{2}=\right.$ 0.9755 ) was close to 1 which indicates actual values and predicted values are satisfactorily correlated [17]. The adjusted determination coefficient (Adj. $\mathrm{R}^{2}$ ) value was 0.9440 , which meant most variation ( $>94.4 \%$ ) of the TFC could be predicted by the model, while only $5.6 \%$ variation could not be explained by the model. The failure of the model to represent the data in the experimental domain at the points was measured by lack-of-fit which were not included in the regression. Adequate precision is used to compare the range of the predicted values at the design points to average prediction error. A ratio greater than 4 indicated adequate model discrimination. In the present study, the value of 16.4 indicated an adequate signal. This model could be used to navigate the design space.

Regression coefficients ( $\mathrm{R}^{2}, \mathrm{Adj}$. and Pred. $\left.\mathrm{R}^{2}\right)$ and corresponding $\mathrm{P}$-values are also presented in table 3. From the P-values of each model term, it was concluded that the independent variables studied (A, C), quadratic terms $\mathrm{A}^{2}$ significantly affected the total flavonoid yield. The results of the study represent that acetone concentration and temperature are the most significant parameters which affect the TFC. 
Table 3: ANOVA for regress equation

\begin{tabular}{|c|c|c|c|c|c|}
\hline Source & Sum of squares & Degree of freedom & Mean square & F-value & P-value (prob>F) \\
\hline Model & 30654.57 & 9 & 3406.06 & 30.97 & 0.000001 \\
\hline A & 6941.95 & 1 & 6941.95 & 63.12 & 0.000004 \\
\hline B & 147.75 & 1 & 147.75 & 1.34 & 0.2844 \\
\hline $\mathrm{C}$ & 2087.87 & 1 & 2087.87 & 18.98 & 0.0033 \\
\hline $\mathrm{AB}$ & 115.78 & 1 & 115.78 & 1.05 & 0.3390 \\
\hline AC & 45.29 & 1 & 45.29 & 0.41 & 0.5415 \\
\hline $\mathrm{BC}$ & 266.67 & 1 & 266.67 & 2.42 & 0.1634 \\
\hline $\mathrm{A}^{2}$ & 20589.75 & 1 & 20589.75 & 187.22 & 0.000001 \\
\hline $\mathrm{B}^{2}$ & 186.14 & 1 & 186.14 & 1.69 & 0.2344 \\
\hline $\mathrm{C}^{2}$ & 32.92 & 1 & 32.92 & 0.30 & 0.6013 \\
\hline Residual & 769.84 & 7 & 109.98 & & \\
\hline Lack of fit & 350.55 & 3 & 116.85 & 1.11 & 0.4417 \\
\hline Pure error & 419.29 & 4 & 104.82 & & \\
\hline Cor total & 31424.41 & 16 & & & \\
\hline $\mathrm{R}^{2}$ & 0.9755 & & & & \\
\hline Adj. $\mathrm{R}^{2}$ & 0.9440 & & & & \\
\hline Pred. $\mathrm{R}^{2}$ & 0.8007 & & & & \\
\hline Adequate precision & 16.397 & & & & \\
\hline
\end{tabular}

\section{2) Analysis of response surfaces}

Interaction effects of the factors on the TFC can be predicted from the three-dimensional response surface plots. The threedimensional response surfaces described the sensitivity of response value towards the change in variables. These plots showed effects of two factors at a time on the response, keeping another factor at zero level.

Fig. 5a represented the effects of acetone concentration and extraction time at a constant temperature of $50^{\circ} \mathrm{C}$ on TFC. It showed that acetone concentration had a major effect on flavonoid yield. The TFC increased with an increase in acetone concentration up to $45 \%$ $\mathrm{v} / \mathrm{v}$ but it decreased when acetone concentration was kept at levels higher than $45 \%$. There is an increase in TFC when extraction time was raised to $102 \mathrm{~min}$ and a further increase in TFC thereafter. Thus an increase in time did not affect extraction process.

The effect of acetone concentration and extraction temperature at constant extraction time $(90 \mathrm{~min})$ could be seen from fig. $5 \mathrm{~b}$. The TFC mainly depended on acetone concentration than temperature. It resulted in a curvilinear increase till $45 \%$ and extraction temperature up to $40{ }^{\circ} \mathrm{C}$. TFC declined with increase in acetone concentration $(>45 \% \mathrm{v} / \mathrm{v})$ at high temperature $\left(>40{ }^{\circ} \mathrm{C}\right)$. Fig. indicated that response TFC changed by changing acetone concentration for a given value of either time or temperature but no change in TFC was found by varying time or temperature for a given value of acetone concentration.

3) Optimization of extraction parameters and validation of model

In this study, the aim was to optimize the extraction parameters using heat reflux method which could show highest TFC. The extraction experiment was carried out for testing the reliability of the experimental method, by adopting the program of the optimal analytical model. Predicted and adjusted extraction conditions are shown in table 4. From the result obtained, the experimental values were consistent with the predictive values and were better than single factor experiments. This confirms that the response model was adequate and reliable for the extraction process (table 4).

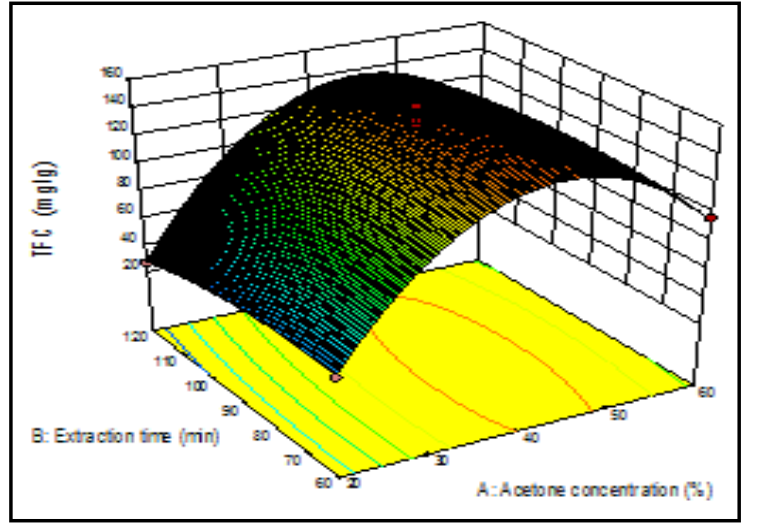

a

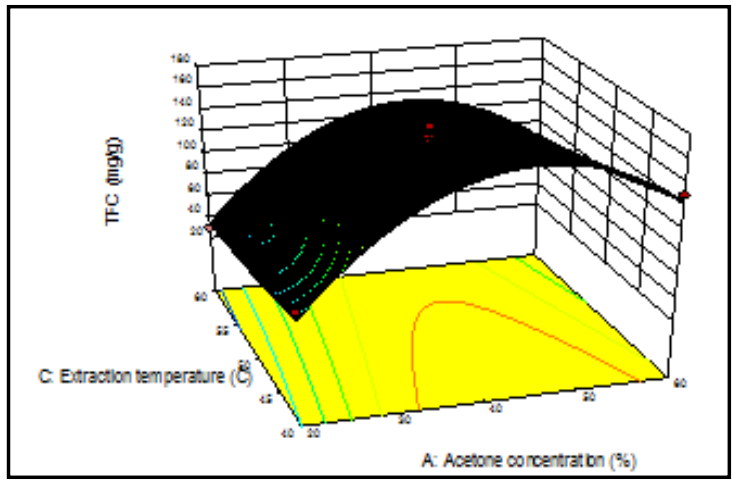

b

Fig. 5 a, b: Response surface (3D) showing the effect of different extraction parameters (A: Extraction Time; B: Acetone concentration; $\mathrm{C}$ : extraction temperature, added on the response)

Table 4: Predicted and experimental values of the responses at optimum conditions

\begin{tabular}{|c|c|c|c|c|}
\hline Term & Acetone concentration $(\% \mathrm{v} / \mathrm{v})$ & Extraction time (min) & Extraction temperature $\left({ }^{\circ} \mathrm{C}\right)$ & Response mg/g \\
\hline Predict & 45.00 & 101.46 & 41.57 & 163.42 \\
\hline Experiment & 45 & 102 & 42 & 161.14 \\
\hline
\end{tabular}

\section{CONCLUSION}

The best yield in extraction process can be achieved by using multivariate optimization, which selects the optimal operating conditions of interrelated variables. Highest flavonoid concentration $(161.14 \mathrm{mg} / \mathrm{g})$ was obtained with acetone concentration of $45.00 \%$ $\mathrm{v} / \mathrm{v}$, time $101.46 \mathrm{~min}$, temperature $41.57^{\circ} \mathrm{C}$ as optimal extracting conditions. RSM proved successful in optimizing the extraction 
conditions to determine TFC of G. gummifera gum resin, as the TFC under the optimized conditions was higher than that of nonoptimized conditions. The regression coefficient and P-value indicated that acetone concentration $(P<0.01)$ and temperature $(P<0.01)$ were significant factors in extraction process affecting TFC.

\section{ACKNOWLEDGEMENT}

Authors are thankful to University Grant Commission for providing financial assistance.

\section{CONFLICT OF INTERESTS}

There is no conflict of interest as per my knowledge

\section{REFERENCES}

1. Naczk M, Shahidi F. Extraction and analysis of phenolics in food. J Chromatogr. A 2004;1054:95-111.

2. Sheng ZL, Wan PF, Dong CL, Li YH. Optimization of total flavonoids content extracted from Flos Populi using response surface methodology. Ind Crops Prod 2013;43:778-86.

3. Pal D, Verma P. Flavonoids: a powerful and abundant source of antioxidants. Int J Pharm Pharm Sci 2013;5:95-8.

4. Wealth of India. A dictionary of Indian raw materials and industrial products, raw materials. BN Sastri. Ed. Council of Scientific and Industrial Research, New Delhi; 2005. p. 109-10.

5. Prabha SP, Ansil PN, Nitha A, Wills PJ, Latha MS. Preventive and curative effect of methanolic extract of Gardenia gummifera Linn. f. on thioacetamide-induced oxidative stress in rat. Asian Pac J Trop Dis 2012;2:90-8.

6. Bas D, Boyaci IH. Modeling and optimization I: usability of response surface methodology. J Food Eng 2007;78:836-45.

7. Pan Y, Zhang J, Shen T, Zuo ZT, Jin H, Wang YZ, et al. Optimization of ultrasonic extraction by response surface methodology combined with ultrafastliquid chromatographyultraviolet method for determination of four iridoids in Gentiana rigescens. J Food Drug Anal 2015;23:529-37.

8. Meda A, Lamien CE, Romito M, Millogo J, Nacoulma OG. Determination of the total phenolic, flavonoid and proline contents in Burkina Fasan honey, as well as their radical scavenging activity. Food Chem 2005;91:571-7.

9. Silva EM, Silva JS, Penab RS, Rogez H. A combined approach to optimize the drying process of flavonoid-rich leaves (Inga edulis) using experimental design and mathematical modeling. Food Bioprod Process 2011;89:39-46.

10. Silva E, Rogez H, Larondelle. Optimization of extraction of phenolics from Inga edulis leaves using response surface methodology. Sep Purif Technol 2007;55:381-7.

11. Uma DB, Ho CW, Wan Aida WM. Optimization of extraction parameters of total phenolic compounds from henna (Lawsonia inermis) leaves. Sains Malays 2010;9:119-28.

12. Naczk M, Shahidi F, Sullivan A. Analytical methods section recovery of rapeseed tannins by various solvent systems. Food Chem 1992;45:51-4.

13. Alasalvar C, Karamacä M, Amarowicz R, Shahidi F. Antioxidant and antiradical activities in extracts of hazelnut kernel (Corylus Avellana L.) and hazelnut green leafy cover. J Agric Food Chem 2006;54:4826-32.

14. Sheng ZL, Li JC, Li YH. Optimization of forsythoside extraction from Forsythia suspensa by box-behnken design. Afr J Biotechnol 2011;10:11728-37.

15. Prommuak C, De-Eknamkul W, Shotipruk A. Extraction of flavonoids and carotenoids from Thai silk waste and antioxidant activity of extracts. Sep Purif Technol 2008;62:444-8.

16. Spigno G, Tramelli L, De Faveri DM. Effects of extraction time, temperature and solvent on concentration and antioxidant activity of marc grape phenolics. J Food Eng 2007;81:200-8.

17. Sinha K, Sahaa PD, Datta S. Response surface optimization and artificial neural network modeling of microwave assisted natural dye extraction from pomegranate rind. Ind Crops Prod 2012;37:408-14.

\section{How to cite this article}

- Snehal B Bhandare, Kirti S Laddha. Optimization of extraction parameters for total flavonoids from Gardenia gummifera gum resin by response surface methodology. Int J Pharm Pharm Sci 2016;8(11):64-68. 